\title{
ROMANCE OR REALITY? : Examining burnout in early childhood teachers
}

\author{
Karen Noble \\ Kym Macfarlane
}

Griffith University, Logan Campus

Relatively high rates of teacher attrition have been consistently identified as a major issue for the teaching profession over several decades. As a result, there has been a growing interest in the wellbeing of teachers across the entire education sector. Recent research by Noble, Goddard and O'Brien (2003) has found that early childhood teachers, on average, maintained significantly lower burnout levels than did other teachers over their first year of service. However, at the beginning of their second year of service early childhood teachers reported significant increases in burnout, in comparison to primary and secondary school teachers who reported more gradual and consistent increases over the initial stages of their careers. The authors of this paper explore these significant statistics and call for further research to be conducted into how early career burnout develops in early childhood teachers. Such an exploration may assist in the reduction of burnout across the early childhood education and care (ECEC) sector.

\section{Introduction}

Most beginning teachers look forward to their initial experience as the facilitators of learning in a classroom. Such teachers can acquire a confidence during their training that they believe prepares them for the experiences of managing and working with children and their families (Brennan, 1998; Corrie \& Maloney, 1996; Gore, 1995; Maloney \& Barblett, 2001). However, current research indicates that a vast majority of these teachers actually 'burnout' very quickly once they begin to practise (Goddard \& O'Brien. 2004). That is, primary teachers begin to burn out from the start, whereas early childhood education and care (ECEC) teachers have demonstrated a quite stable first year before the burnout process becomes evident (Noble, Goddard \& O'Brien, 2003). Clearly, this rate of burnout of both primary and ECEC teachers needs to be addressed if the teaching profession is to maintain some kind of stability.

Noble, Goddard and O'Brien (2003) argue that the beginning phase of the teaching career unquestionably influences one's abilities and expertise as a professional practitioner. Conditions experienced at this time can substantially influence the level of effectiveness the teacher is able to achieve and maintain throughout her/his career, and also influence the decision on whether or not to continue in the teaching profession.
Therefore it is imperative that the experiences of beginning teachers tend to be positive. Additionally, Noble, Goddard and O'Brien (2003) present findings of a longitudinal study that pinpoints the burnout of beginning teachers and highlights significant differences between primary, secondary and early childhood sectors.

What is of interest in our own paper is the initially slower rate of burnout for ECEC teachers in the study. While Noble, Goddard and O'Brien (2003) present only initial findings, the different rates of burnout between beginning primary and ECEC teachers highlighted an interesting anomaly. It can be argued that the above paper presents only one perspective. However, additional literature regarding burnout is used in our own paper to affirm the importance of further investigation (Fuller, 1969: Ryan, 1986; Sumsion, 2003; Williams, 1995). Moreover, our paper concerns itself with questioning how it is possible for ECEC teachers to achieve and maintain a high level of effectiveness throughout the beginning phase of their career, i.e. in the first 12 months. We argue that the different rates of burnout in beginning primary teachers and beginning ECEC teachers require examination, as it is possible that they are indicative of different philosophies and preparation in preservice training that affect how beginning teachers cope. Furthermore, an argument is presented to explore 
how certain differences in preservice preparation might inform mutually beneficial reflection and improvement on the preparation of teachers for the field.

The main argument presented in our paper is that ECEC teachers participate in preparation programs that sometimes support highly romanticised images of childhood. These images produce notions of 'ideal' or 'better' children, in terms of psychologised constitutions of propriety (Tyler, 1993). We argue that these psychologised images and romanticised ideals (Jenks, 1996a; 1996b; Sumsion, 2003) contribute to early burnout of ECEC teachers, rather than assisting them to deal with ECEC as it occurs in the current societal context. Additionally, it is argued that other issues also contribute to the burnout rates. Issues such as demographic positioning, individual and systemic support networks and workplace environments all play a role in undermining the idealism of the beginning ECEC teacher. A thorough examination of all of these issues must be undertaken.

\section{Idealised approaches}

Historically, traditional grand narratives strongly positioned in psychological theory, in particular that of developmentally appropriate practice (DAP), have governed the field of ECEC (Australian Early Childhood Association, 1992; Brennan, 1998; Fleer, 2000; Grieshaber \& Cannella, 2003; James, Jenks \& Prout, 1998; Moss, 2002). Researchers have argued that such an approach limits the way teachers interact with young children and their families (Noble, 2003; Grieshaber \& Canella, 2003). However, more recent innovative research by Jennifer Sumsion (2003) has highlighted specifically how idealised and romanticised images of children and their families impact upon the way ECEC teachers engage in practice.

Sumsion (2003) argues that romantic notions of practice do not withstand the complexity, uncertainty and insecurity of working with young children and their families in the current context (Hultqvist \& Dahlberg. 2001; Jenks, 1996a; 1996b; Lyotard, 1984). Adherence to such romanticised approaches must be addressed, so that these notions do not delimit how ECEC teachers might practise. Multiple perspectives and understandings are preferable, particularly in the early career phase, to inform the practice of new teachers. Sumsion uses Phelan's argument, which contends that preservice teachers should be exposed to a wider range of discourses than are traditionally sanctioned by teacher education programs' (cited in Sumsion, 2003. p. 83). Furthermore, Phelan states that:
... [practitioner] education needs to become a discursive project. There is no escaping discourse. There is no escaping that language/discourse constitutes experience generally, and our experience of place specifically. [Teacher] educators may need to consider how we can help prospective practitioners to recognize the multiple discourses that shape and often restrict their thinking about experience and place (cited in Sumsion, 2003 p. 19).

Thus, if discourse constitutes the experience of preservice ECEC teachers, then traditional grand narratives have the power to produce a 'regime of truth' (Foucault, 1980) about proper ECEC practice which beginning teachers could adhere to. Therefore, it is possible for this discursive organisation to idealise work with young children and their families, in such a way as to inhibit practitioner understanding that multiple realities for young children and their families are possible (Popkewitz, 2000). Consequently, beginning teachers may struggle to reconcile ideal notions of how practice should be conceptualised within the complex reality of work with young children and their families. Stringent adherence to romanticised notions of children, families and childhood could contribute to beginning ECEC teachers' disillusionment.

\section{Demographics}

The placement of beginning teachers in Queensland, in the government system, tends to be an arbitrary process, and such demographic constraints can contribute to burnout (Schools Council, National Board of Employment, Education and Training, 1990; Wideen \& Grimmett, 1995). It is not uncommon for beginning teachers to be placed in positions many kilometres from their family home. Additionally, many positions for beginning teachers are in rural or isolated locations, further compounding the teacher's adjustment to the work environment (Australian Bureau of Statistics, 2003). This demographic isolation can be problematic, since personal support networks are no longer present.

In the early stages of a teacher's career, strong professional networks are vital to ensure that the teacher remains confident undertaking a role in the pedagogical process. Furthermore, both personal and professional networks are necessary, so that teachers have the opportunity to critically reflect and debrief on issues that arise. In recent times there has been a growing emphasis on reflective practice as a means of assisting professionals to respond to the complex nature of the workplace (Brookfield, 1995; Moss, 2000; 
Patterson \& Sumsion, 1996: Schon. 1991). Many researchers cite reflection or reflexivity as a means of objectively examining methods of practice and policy formation in order to instigate positive change (Ebbeck \& Waniganayake, 2003; Johansson, 2003; Mayall, 1994. 1999; Sumsion, 2003). Thus positive change is less likely to occur within a framework where collegial support is lacking. The isolation teachers experience effectively limits opportunities for dialogue pertaining to practice. As practitioners' knowledge 'is constructed out of a dialogic relationship that exerts a dynamic and reciprocal influence between theory and practice' (Corrie \& Maloney, 1996 p. 71), this isolation can compound existing problems of adjustment.

Moreover, isolation adds to emotional and social insecurities that can have an impact upon the beginning teachers' sense of wellbeing (Noble, 2003). Social and emotional adjustment can be a time-consuming process and, in the early stages of one's teaching career, time is of the essence. As the workload of beginning teachers is substantial, there is often very little time to promote and re-establish the professional networks important to maintaining innovative and quality practice (Martin, 200I). Beginning teachers' substantial workload may also inhibit their ability to establish and reconnect with important personal contacts. Thus demographic isolation can impact on both professional and personal wellbeing of newly established teachers and contribute to early burnout of all beginning teachers.

In relation to ECEC teachers, these issues become more problematic. Romantic notions of what practice should look like do not sit easily within the confines of demographic isolation. Further, while the organisation of primary and secondary classrooms allows for greater networking opportunities, because of increased numbers of personnel, this is not true for the ECEC sector. Subsequently, while beginning primary and secondary teachers may have a greater opportunity to share specialised knowledge, ECEC teachers may not have the same opportunity. ECEC teachers' understanding of proper practice could well be affected by an inability to frequently network with colleagues who share similar philosophies. Adherence to romanticised grand narratives is difficult to maintain without a shared vision and dialogue being promoted. These grand narratives do not necessarily inform the practice of primary and secondary teachers. and so support may not be found from these colleagues. Thus. ECEC teachers may experience feelings of frustration and inadequacy as they struggle to maintain ideal practices in varied settings.

\section{Systemic support networks}

Within the literature describing the experiences of beginning teachers (Dempster, Sim, Beere \& Logan, 2000; Elkerton, 1984: Fimian \& Blanton, 1987; Fuller. 1969; Ryan, 1986; Williams, 1995) themes of initial overwhelm are common in the early stages. In fact, research (e.g. New South Wales Department of School Education, 1992) undertaken with beginning teachers has consistently reinforced the need for ongoing professional support. Ongoing professional support. quite apart from supervision, is needed for constructive reflection and learning about the teaching and socialisation processes. Although the initial preparation and induction of beginning teachers is a well-researched area (Corrie \& Maloney, 1996; Fleer, 2000: Maloney \& Barblett, 2001; Martin, 200I), there is a frustration evident concerning the lack of constructive and comprehensive change.

Preservice training programs and their agents are merely the first, yet potentially the most important, support structure a prospective teacher needs. From this point of view, preservice training could realistically be considered as a comprehensive program of preservice induction. If university preparation were to be viewed not separate from, but as the initial step in, a staged/progressive induction program, research into beginning ECEC teacher perceptions of their preservice training would be more integrated with research on beginning teacher experiences at the workplace. The authors suggest that what is currently available for all beginning teachers in the area of preservice and postservice induction might well be inadequate.

In Queensland particularly, existing induction and support programs for beginning ECEC teachers are usually administered in conjunction with those for teachers beginning their careers in the primary education sector (Corrie \& Maloney, 1996; Maloney \& Barblett, 2000; Noble, Goddard \& O'Brien, 2003). As the way most primary classrooms generally operate is very different from those of ECEC, it can be assumed that the philosophical approaches also differ. However, because of the smaller numbers of ECEC teachers, the focus of these programs is generally orientated more towards the primary classroom (Noble, Goddard \& O'Brien, 2003). Yet, in the secondary sector, the beginning secondary teachers receive separate induction from their primary colleagues in most cases. delineating an accepted difference in approach between secondary and primary classrooms. Thus, the way the induction program operates, there is no accepted 
distinction between primary and ECEC teachers even though there is a philosophical difference. The identity of ECEC teachers is blurred from the outset, meaning that they are more isolated in the beginning phase of their career and lack a distinct identity, making it difficult for them to maintain professional direction in their work. This lack of identity may well contribute to the different rates of burnout. Romanticised notions of children, families and childhood that contribute to discourses producing particular methods as 'the right way to teach' could possibly sustain ECEC teachers than more pragmatic approaches would. Such romanticised notions explicit to the strong philosophies of ECEC tend to produce commitment to the ideal, rather than simply dealing with the reality. Therefore, such commitment to an 'always possible ideal may sustain ECEC teachers for a longer period.

\section{Workplace environments}

Moreover, the difference in philosophical approach affects the positioning of the ECEC teacher in the workplace. Eighty per cent of principals in the Queensland state education system are male (ABS, 2003). Given that only a small percentage of ECEC teachers are male (ABS, 2003), the likelihood of the leader of the school curriculum having a strong background in ECEC philosophy is very small. While gender is not an issue being raised here, it is useful to highlight that, statistically, there is likely to be very few principals of primary schools who are able to act in a supportive mentoring role that reinforces the ECEC philosophy. This issue, coupled with pressure from government policy directives (Queensland Government, 2002), administrators and parents for a more formal approach to ECEC, presupposes disharmony and fragmentation in the way programs for children are delivered. Thus the ECEC teacher may well be powerless to instigate effective and, in the teacher's view, ideal environments for young children. In this way, the ECEC teacher may suffer both isolation and powerlessness. Again, romanticised ideals that produce 'truth' about effective ECEC teaching may allow the $E C E C$ teacher to persevere for longer periods, as these tend to identify an 'alternative' approach to practice.

\section{Transition from university to the ECEC field}

The conditions of the initial teaching experience substantially influence the level of effectiveness a teacher is able to achieve and maintain throughout their career. Initial teaching experiences also influence the decision as to whether or not to continue in the profession (Corrie \& Maloney, 1996; Noble, Goddard \& O'Brien, 2003). This initial experience may well be negative and not pleasurable. Although these beginning practitioners have undertaken substantial study, usually in the form of a four-year undergraduate degree program, the issues mentioned above and the literature state resoundingly that beginning practitioners are illprepared for their chosen career as teachers (Dempster, Sim, Beere \& Logan, 2000; Elkerton, 1984: Fimian \& Blanton, 1987; Fuller, 1969; Ryan, 1986; Williams, 1995).

\section{Patterns of burnout}

The issues highlighted in this paper demonstrate the importance of examining the reasons for early burnout of beginning teachers. What has not yet been fully explored, however, are the reasons for the difference in patterns of burnout between ECEC teachers and other beginning teachers. It is well established that early burnout is a significant problem for beginning teachers (Dempster, Sim. Beere \& Logan, 2000: Elkerton, 1984; Fimian \& Blanton, 1987; Fuller, 1969; Ryan, 1986; Williams, 1995). However, the difference in patterns of burnout between primary teachers and ECEC teachers must be further researched, in order to understand why ECEC teachers suffer burnout during their second year of practice and what impact this has.

Although it can be argued that some of these aspects relating to burnout may represent generalisations, they are nonetheless illuminating. In reality, the divisions between beginning ECEC and primary teachers are likely to exist on a continuum, rather than being clearly defined. For example, it is possible that some primary teachers have romanticised notions and visions of childhood and that some ECEC teachers do not. What can be argued, however, is that romanticised notions of childhood and psychologically-based practice that form part of the discourse of ECEC (Fleer, 2000; Grieshaber \& Canella, 2001; Sumsion, 2003) produce ECEC teachers in particular ways, privileging such notions of practice as proper. Thus it is likely that these notions are more a part of ECEC practice than that of primary teachers. As such, they represent the most prominent differences between beginning ECEC teachers and their primary counterparts. This fact is supported by Sumsion's (2003) research, which highlights romanticised and idealistic approaches as possible reasons for ECEC teachers deserting the field. 


\section{Further research}

What can be established is that further examination of the reasons pertaining to early burnout of beginning ECEC teachers is necessary. Moreover, it would be useful to understand more completely what sustains ECEC teachers in their first year as a way of redressing burnout in the sector. It is evident that mitigating factors occur during the first years of practice, and these factors require identification and examination.

\section{Conclusion}

This paper has highlighted the difference between ECEC teachers and primary teachers in relation to patterns and rates of burnout. It is suggested that the discursive organisation of ECEC, which privileges romanticised notions of childhood and practice, may well be a contributing factor in relation to burnout and wellbeing. Further research is recommended in order to determine how significant these notions are to ECEC teachers and what other factors contribute to burnout in their early career phase. This research may lead to a reconceptualisation of existing preparation and induction for beginning ECEC teachers, or the implementation of a separate ECEC induction. And further of issues pertaining to other groups of beginning teachers may well be uncovered.

\section{References}

Australian Bureau of Statistics (2003). Australia now - a statistical profile: Population. Population distribution. Retrieved 20 May 2003. http://www.abs.gov.au.

Australian Early Childhood Association (1992). AECA code of ethics. Canberra: Australian Early Childhood Association.

Brennan, D. (1998). The politics of Australian child care: Philanthropy to feminism and beyond. Melbourne: Cambridge University Press.

Brookfield, S. (1995). Becoming a critically reflective teacher. San Francisco: Jossey-Bass.

Corrie, L., \& Maloney, C. (1996). An alternative school based field experience program for 3 rd year teacher education students. Paper presented at the Australian Research in Early Childhood Conference, University of Canberra.

Dempster. N., Sim. C.. Beere, D.. \& Logan, L. (2000). Teachers in Australian schools: A report from the 1999 notional survey (final report). Canberra: Australian College of Educators.

Ebbeck, M., \& Waniganayake, M. (2003), Eariy childhood professionals: Leading today and tomorrow. Sydney: MacLennan \& Petty.

Elkerton, C. A. (1984). An investigation of stress experienced by beginning teachers during practice teaching. South Africon Journal of Education. 4(3), 97-102.

Fimian, M. J., \& Blanton. L. P. (1987). Stress, burnout, and role problems among teacher trainees and first-year teachers. Journal of Educotion, 8, 97-102.
Fleer, M. (2000). An early childhood research agenda: Voices from the field. Canberra: Department of Education. Training and Youth Affairs.

Foucault. M. (1980). Truth and power. In C. Gordon (Ed.). Power/knowledge: Selected interviews and other writings, 1972-77 (pp. 109-133). New York: Pantheon.

Fuller, F. (1969). Concerns of teachers: A developmental conceptualisation. American Educational Research journal, 6(2). 207-226.

Goddard, R. C., \& O'Brien, P. (2003). Perceptions of well-being in teachers during their first year of employment. Paper presented at the Hawaii International Conference on Social Sciences, Honolulu.

Gore, J. (1995). Emerging issues in teacher education: Innovative Links Project. Perth: Murdoch University.

Grieshaber, S., \& Cannella, G. (Eds.) (2001). Embracing identities in early childhood education: Diversity and possibilities. New York: Teachers College Press.

Hultqvist, K., \& Dahlberg. G. (2001). Governing the child in the new millennium. New York: Routledge Falmer.

James, A., Jenks, C., \& Prout, A. (1998). Theorizing childhood. Cambridge, UK: Polity.

Jenks, C. (1996a). Childhood. London: Routledge.

Jenks, C. (1996b). The postmodern child. In J. Brannen \& M. O'Brien (Eds.), Children in families: Research and policy (pp. 13-24). London: Falmer.

Johansson, f. (2003). Will there be any preschool teachers in the future? A comment on the present Swedish reform of teacher education. Paper presented at the 13th European Early Childhood Education Research Association Conference. University of Strathclyde, Glasgow.

Lyotard, J. F. (1984), The postmodern condition: A report on knowledge. Manchester: Manchester University Press.

Maloney, C., \& Barblett, L. (200I). Teachers' views of the US professional standards in early childhood education. Australian Research in Early Childhood Education, 8(1). 52-60.

Martin, S. (2001). Competency fromework for teochers. Perth: Education Department of Western Australia.

Mayall, B. (1994). Children's childhoods: Observed and experienced. London: Falmer.

Mayall, B. (1999). Critical issues in social research. Philadelphia: Open University Press.

Moss. P. (2000). Training of early childhood education and care staff. International Journal of Educational Research, 38, 31-53.

Moss, P. (2002). Getting beyond childcare: Reflections on recent policy and future possibilities. In J. Brannen \& P. Moss (Eds.). Rethinking children's care (pp. 25-44). Buckingham: University Press.

New South Wales Department of School Education (1992). Review of Australian Teacher Induction. Sydney: Government Printing Office.

Noble, K. (2003) Graduate programs for students working in the ECEC sector. Refereed paper submitted to the New Zealand Association of Research in Education/Australian Association of Research in Education Conference, Auckland.

Noble, K., Goddard, R., \& O'Brien, P. (2003). Beginning teacher comments about preservice education and their suggestions for future preservice training programs. Refereed paper presented to Griffith Institute of Higher Education Conference, Brisbane. 
Patterson, C., \& Sumsion, J. (1996). Linking theory and practice in early childhood teacher education. Paper presented at the Australian Research in Early Childhood Education Symposium, University of Canberra.

Popkewitz, T. (2000). The denial of change in educational change: Systems of ideas in the construction of national policy and evaluation. Educational Researcher, 29(1). 17.29.

Queensland Government (2002). Queensland the Smart State. Education and training reforms for the future. Brisbane: Department of the Premier and Cabinet.

Ryan, K. (1986). The induction of new teachers. Bloomington, IN: Phi Delta Kappa Education Foundation.

Schon, D. (|991). The reflective practitioner: How professionals think in action. London: Arena.
Schools Council, National Board of Employment, Education and Training. (1990). Australia's teochers: An agenda for the next decade. Canberra: Australian Government Printing Service.

Sumsion. J. (2003). Rereading metaphors as cultural texts: A case study of early childhood teacher attrition. The Australion Educational Researcher, 30, 67-88.

Tyler, D. (1993). Making better children. In D. Meredyth \& D. Tyler (1993) (Eds.). Child and citizen: Genealogies of schooling and subjectivity (pp. 35-60). Brisbane: Institute for Cultural and Policy Studies, Griffith University.

Wideen, M.. \& Grimmett. P. (1995). Changing times in teacher education: Reconstructuring or reconceptualizing. London: Falmer.

Williams, D. (1995). Beginning primary school teaching. Paper presented at the Australian Association for Research in Education, Hobart.

www.earlychildhoodaustralia.org.au

\section{Early Childhood Australia}

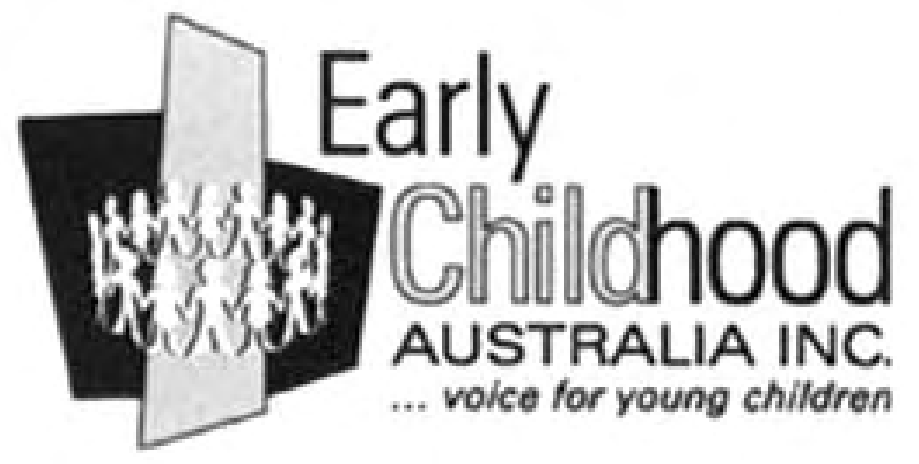

Established in 1938, Early Childhood Australia is:

- a national peak body, non-profit organisation

- a leading specialist early childhood publisher

- promoting high quality services for children from birth to eight.
- Advocacy
- Publications
- Membership

\section{Find out more:}

1800356900 (freecall)

\section{www.earlychildhoodaustralia.org.au}

